\title{
Study on the Optically Transparent Near-Field and Far-Field RFID Reader Antenna
}

\author{
Yuan Yao, Junsheng Yu, and Xiaodong Chen \\ Beijing Key Laboratory of Work Safety Intelligent Monitoring, School of Electronic Engineering, Beijing University of \\ Posts and Telecommunications, No. 10 Xitucheng Road, Beijing, China \\ Correspondence should be addressed to Yuan Yao; yaoy@bupt.edu.cn
}

Received 18 November 2013; Accepted 8 February 2014; Published 13 March 2014

Academic Editor: Chaowei Wang

Copyright (c) 2014 Yuan Yao et al. This is an open access article distributed under the Creative Commons Attribution License, which permits unrestricted use, distribution, and reproduction in any medium, provided the original work is properly cited.

\begin{abstract}
A study on the optically transparent RFID reader antenna which can operate in both near-field and far-field is proposed in this paper. The antenna with a dimension of $45 \mathrm{~mm} \times 45 \mathrm{~mm}$ is fabricated using Indium tin oxide film and can operate from 915 to $935 \mathrm{MHz}$ covering the China UHF RFID band. The strong and uniform magnetic field is excited by magnetic dipole source. Both simulation and measurement results are shown to illustrate the performance of the proposed antenna. The measured reading distances are up to $40 \mathrm{~mm}$ and $100 \mathrm{~mm}$ for near-field and far-field applications, respectively.
\end{abstract}

\section{Introduction}

Recently, UHF RFID systems are getting more and more attention in a number of practical applications, due to automatic identification for efficiently tracking and managing objects. Based on types of objects and applications, inductively coupled near-field working mode is used to transfer information between reader and tag. Near-field reading can be useful for objects having metals and liquids in their vicinity, because normal far-field tags' performance is affected by the presence of these objects $[1,2]$. Farfield communication is widely used due to its long read range. Due to promising performance at item-level tagging (ITL) of small, expensive, and sensitive objects and different applications such as pharmaceutical logistics and biosensing applications, it is considered as a possible solution for ITL in pharmaceutical and retailing industry.

To design a near-field and far-field UHF RFID antenna, some structures have been presented. Shrestha et al. use a segmented loop and a patch, respectively, to achieve nearfield and far-field operations, but they have too large size of $184 \mathrm{~mm} \times 174 \mathrm{~mm}$ [3]. Borja et al.s antenna has a dimension of $72.3 \mathrm{~mm} \times 72.3 \mathrm{~mm}[4]$.

UHF RFID systems present several opportunities, for instance, in clothing stores. One such case would be the possibility to automatically read the tag associated with a piece of clothing being tried on in front of a mirror. However, the conventional reader antennas made of metals damage the sensory experience of the clients. Thus, an RFID reader antenna which can ensure invisibility of the antenna is expected. This feature is attractive for aesthetical reasons and to avoid that clients feel uncomfortable with unusual devices in the fitting room. The antenna cannot be hidden behind the mirror because this is not electromagnetically transparent. Therefore, we propose in this paper to print an optically transparent antenna on the glass surface of the mirror.

There are currently several possible materials to create transparent antennas, like spray-on conductive substances [5] or metallic conductive films. However, most of these materials do not present the best optical transparency for the mirror application. Indium tin oxide (ITO) films seem to be the most viable solution so far, for they present the best compromise between optical transparency and electrical conductivity. Even though the associated ohmic losses reduce the performance of the antenna, there are ways, such as some particular deposition techniques [6], to improve conductivity.

In this paper, an optically transparent UHF RFID reader antenna is proposed with simple and compact configuration for both near-field and far-field operations. The impedance bandwidth is suitable for China standard $(920-925 \mathrm{MHz})$, and it can provide the strong and uniform magnetic field in an adequate interrogation zone. Both simulation and 


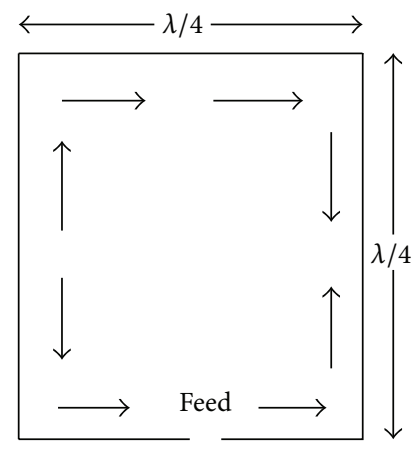

(a)

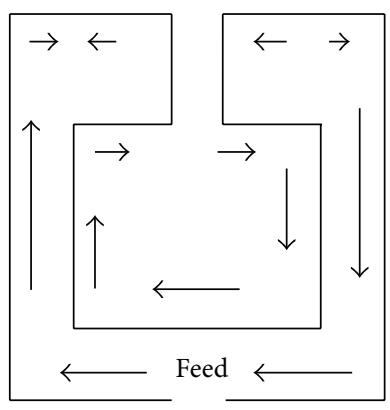

(b)
FIGURE 1: Current distributions of (a) one-wavelength-perimeter loop and (b) folded-dipole loop.

measurements results are provided to illustrate the good performance of the designed antenna.

\section{Antenna Design}

Loop antennas are commonly used for inductively coupled near-field RFID systems. At UHF band, the optimal size of the loop antenna is electrically large or comparable to the wavelength. The amplitude and phase distribution of the current, in the case, is not uniform, and it reverses at every half-wavelength, which results in a weak and nonuniform magnetic field at the center of the loop [7], as shown in Figure 1(a). Some ideas were proposed to solve the problem of current reverse. A segmented loop antenna can avoid in-phase of current [8]. Dual-dipoles also can achieve a uniform magnetic field in near-field region for pure near-field operation [9].

A novel folded-dipole loop antenna was proposed as shown in Figure 1(b). This antenna can achieve a uniform magnetic field easily and has a good far-field gain. The foldeddipole is fabricated using ITO film. The electrical properties of ITO films are specified through the sheet resistance and coating thickness. In this design, an ITO film with sheet resistance equal to $7 \Omega / \mathrm{sq}$ and coating thickness equal to $250 \mathrm{~nm}$ is selected for the antenna. The ITO film is printed on the polyethylene terephthalate with thickness of $0.1 \mathrm{~mm}$ and permittivity of 2.25. Detailed dimensions are shown in Figure $2, s=3 \mathrm{~mm}, s 1=8.5 \mathrm{~mm}$, the antenna size is $L$ $(45 \mathrm{~mm}) \times L(45 \mathrm{~mm})$, and line width is $1 \mathrm{~mm}$.

\section{Results and Discussion}

Simulations and optimizations were performed using Ansoft High Frequency Structure Simulator (HFSS) software, which uses the finite element method (FEM).

Figure 3 shows the fabricated antenna after parameter optimization. The measured $S_{11}$ agrees with the simulated one with a slight deviation to the right side by $1 \mathrm{MHz}$ as shown in Figure 4. The measured bandwidth ranges from 916 to $936 \mathrm{MHz}$, which covers the China UHF RFID band.

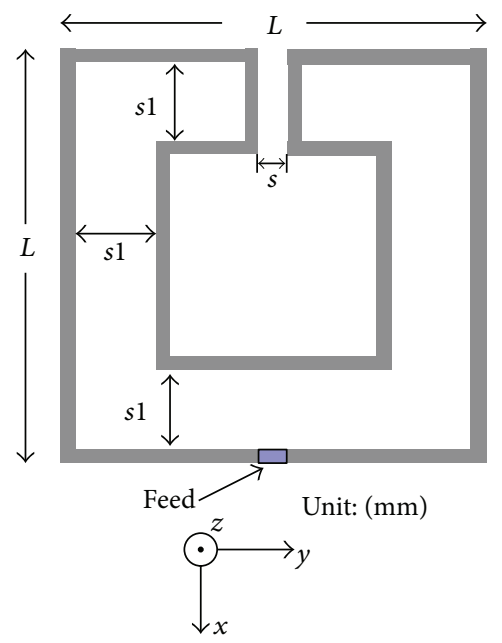

FIGURE 2: Prototype of the folded-dipole loop antenna.

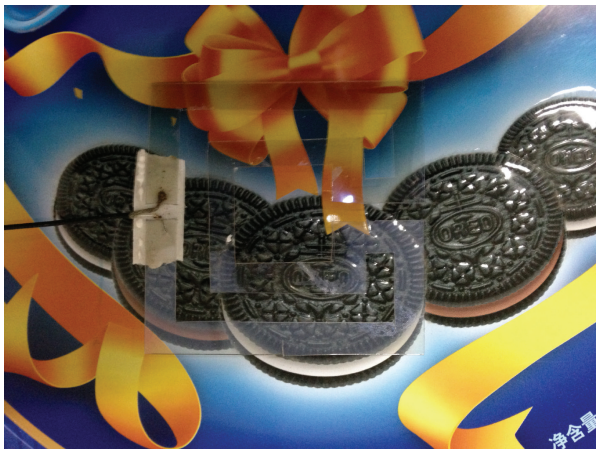

FIGURE 3: Photograph of the fabricated antenna.

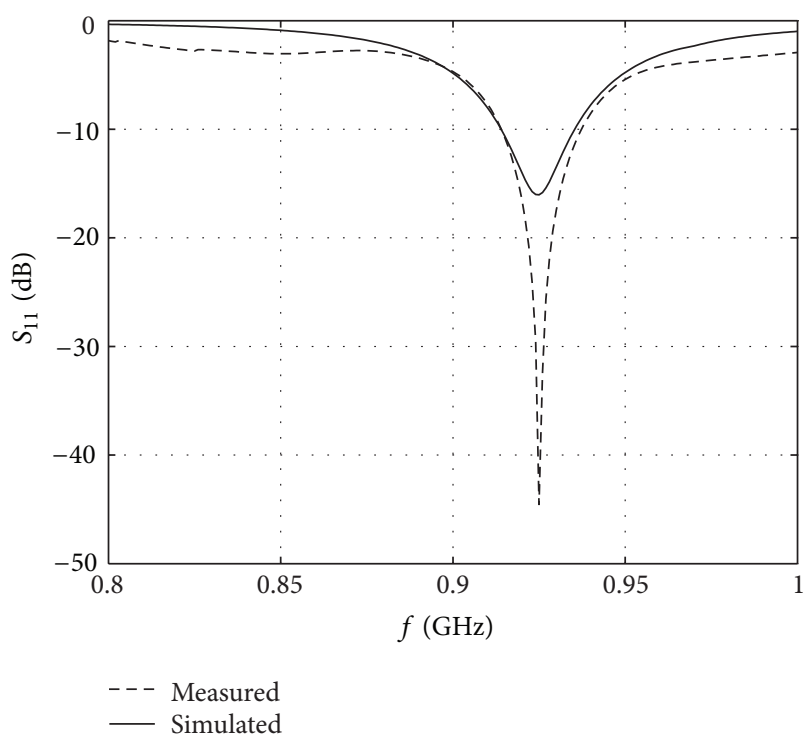

FIGURE 4: Simulated and measured $S_{11}$ of the antenna. 


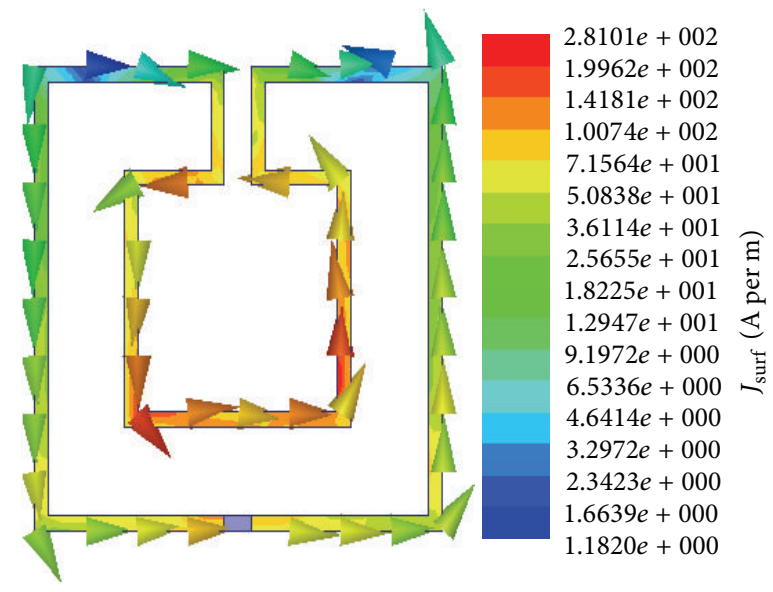

FIGURE 5: Simulated current distribution on the antenna.

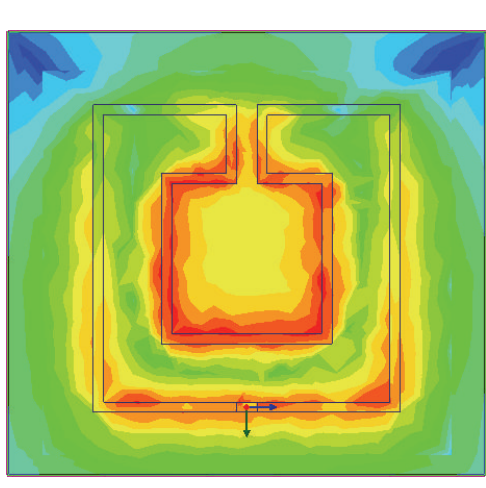

(a)

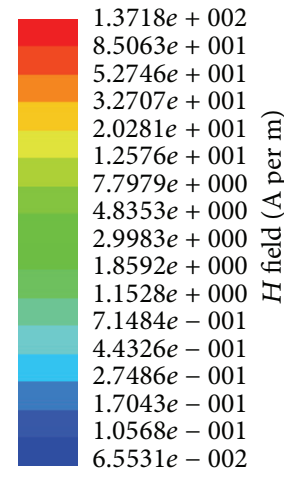

$.0568 e-001$
$6.5531 e-002$
The simulated current distribution along this foldeddipole loop is shown in Figure 5. We can see that the current reverses at the outer loop, however, which is unidirectional along the inner loop. Figure 6 shows the resulting $z$-component of the magnetic field on an $x y$-plane above the antenna at $z=0$ and $z=10 \mathrm{~mm}$. We can see that the field distribution is uniform in the center region.

Based on the fabricated antenna, we measure the read range and width by using the Impinj UHF button. The test scene is presented in Figures $7(\mathrm{a})$ and $7(\mathrm{~b})$ and shows the prototype of the Impinj UHF near-field tag whose diameter is around $1 \mathrm{~cm}$. Under the transmission power level of $15 \mathrm{dBm}$, the measured reading distance is $40 \mathrm{~mm}$. When the tag is attached to a water-item container, the reading range is still the same. Additionally, a far-field tag is also measured, and reading range is around $100 \mathrm{~mm}$ due to the good far-field gain of the reader antenna. When the far-field tag is attached to the bottle of water, the reading range is reduced to $4.5 \mathrm{~mm}$.

Figure 8 shows the measured reading range at different distances between the reader antenna and tag. We use the square lattice; its size is $1 \mathrm{~cm} \times 1 \mathrm{~cm}$.

The simulated and measured radiation patterns of the proposed antenna are, respectively, shown in Figure 9 which makes the antenna suitable for far-field application. It can be seen that the gain of the antenna is relatively low compared with this kind of antenna made of metals, because the conventional metal antenna can achieve the gain of $0 \mathrm{dBi}$ under the same structure. But the reading range can achieve $1 \mathrm{~m}$ when we use a far-field UHF RFID tag and the transmission power of the reader is $30 \mathrm{dBm}$. So even though the gain of the proposed antenna is low because of the ohm loss of the ITO film, the capability of reading far-field tag is good enough.

\section{Conclusion}

In this paper, a novel UHF reader antenna was proposed for near-field and far-field simultaneous operations. A magnetic dipole was folded to produce a uniform magnetic field distribution at UHF. This RFID reader antenna is designed for the China UHF RFID band. With the Impinj UHF button near-field tag, the maximum read range obtained was $40 \mathrm{~mm}$ under $15 \mathrm{dBm}$ transmission power. The near-field reading performance was not degraded when the tag was attached to a water container. The far-field read range, with a commercial far-field tag, was approximately $100 \mathrm{~mm}$. This novel RFID 


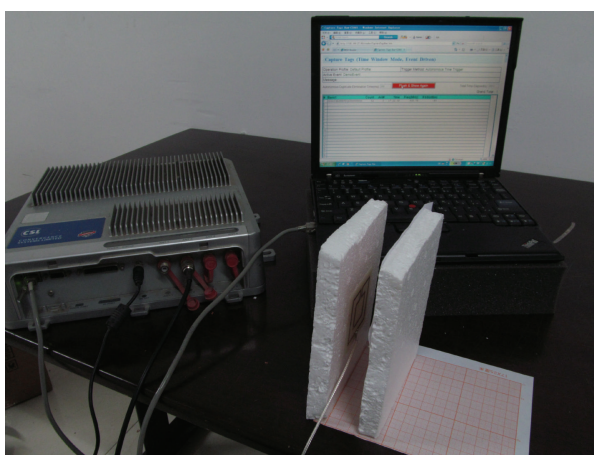

(a)

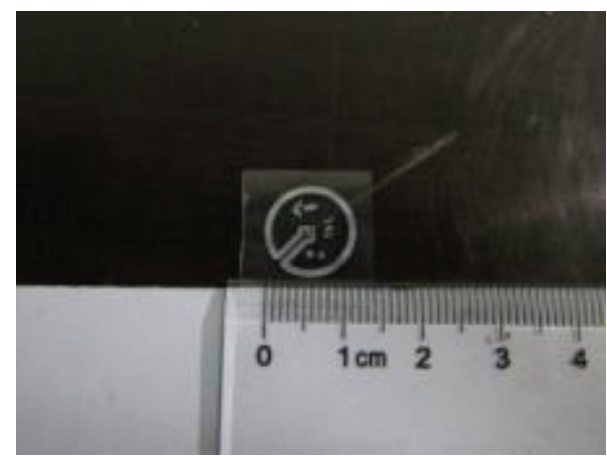

(b)

FIGURE 7: Antenna measurement. (a) Test scene of read range measurement. (b) Impinj UHF button near-field tag.

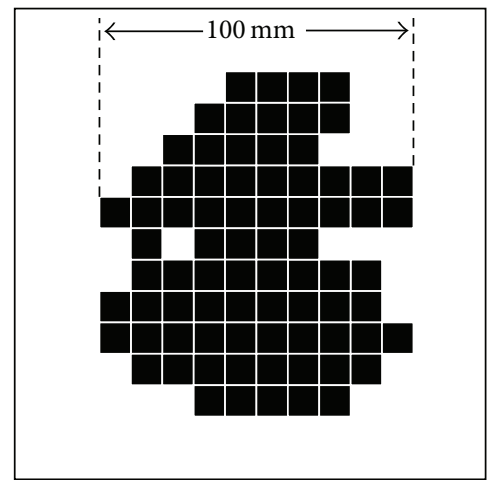

(a)

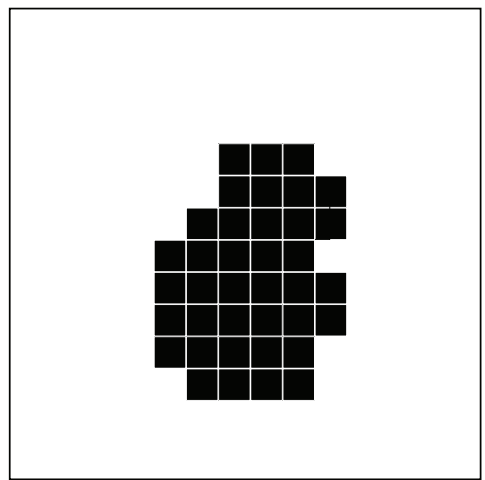

(b)

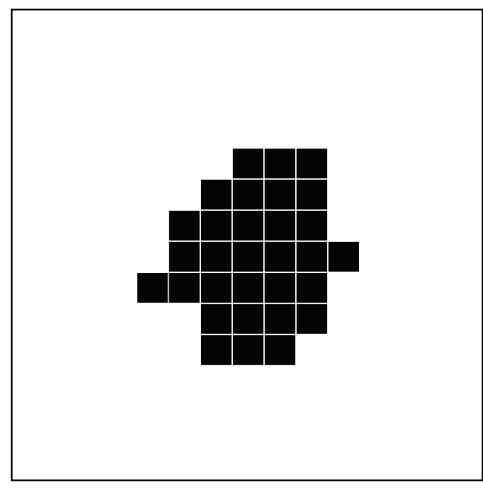

(c)

Figure 8: Measured read width at $x y$-plane. (a) $z=10 \mathrm{~mm}$, (b) $z=20 \mathrm{~mm}$, and (c) $z=40 \mathrm{~mm}$

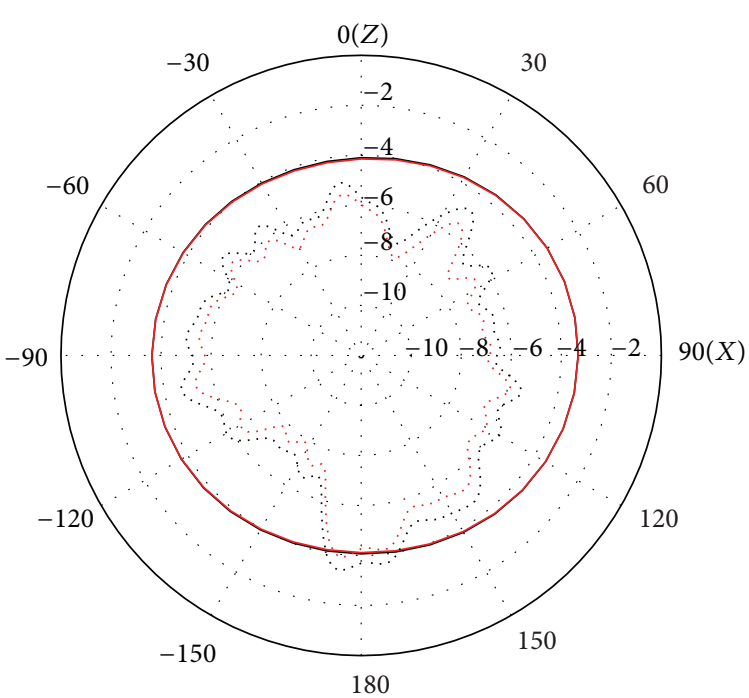

- Simulated $920 \mathrm{M}$ Measured 920M

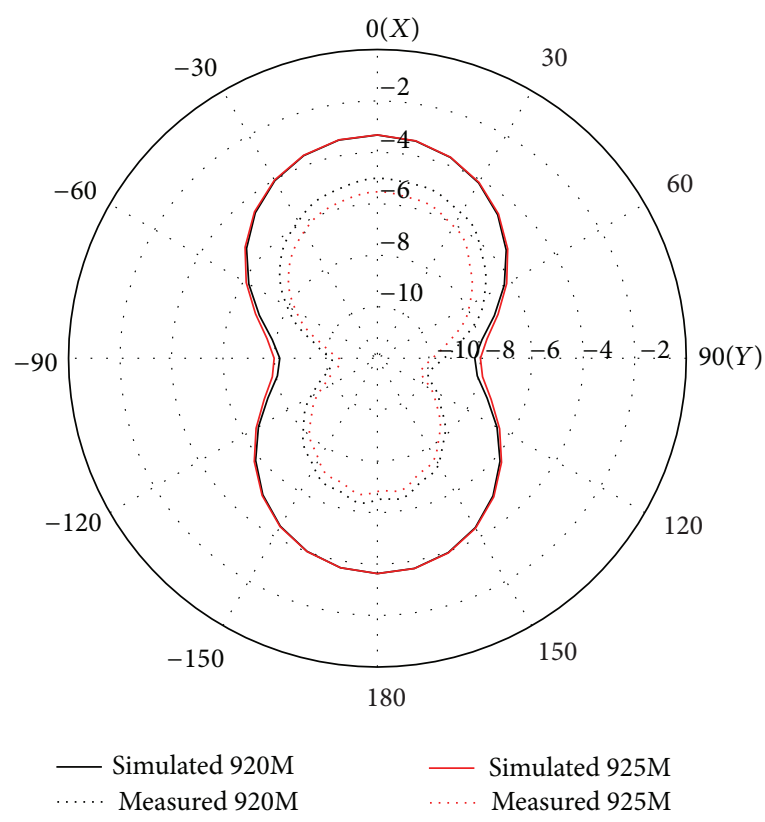

(b)

FIGURE 9: Simulated and measured far-field radiation patterns at (a) $x z$-plane and (b) $x y$-plane. 
reader antenna can be applied for near-field and far-field operations.

\section{Conflict of Interests}

The authors declare that there is no conflict of interests regarding the publication of this paper.

\section{Acknowledgments}

This work is supported by the National Natural Science Foundation of China under Grant no. 61201026, Beijing Natural Science Foundation (4133091), and Beijing Higher Education Young Elite Teacher Project (Grant no. YETP0438).

\section{References}

[1] D. M. Dobkin and S. M. Weigand, "Environmental effects on RFID tag antennas," in Proceedings of the IEEE MTT-S International Microwave Symposium, pp. 135-138, June 2005.

[2] X. Qing, Z. N. Chen, and C. K. Goh, "Platform effect on RFID tag antennas and co-design considerations," in Proceedings of the IEEE Microwave Conferenc, pp. 1-4, December 2008.

[3] B. Shrestha, A. Elsherbeni, and L. Ukkonen, "UHF RFID reader antenna for near-field and far-field operations," IEEE Antennas and Wireless Propagation Letters, vol. 10, pp. 1274-1277, 2011.

[4] A. L. Borja, A. Belenguer, J. Cascon, and J. R. Kelly, "A reconfigurable passive UHF reader loop antenna for near-field and far-field RFID applications," IEEE Antennas and Wireless Propagation Letters, vol. 11, pp. 580-583, 2012.

[5] F. Colombel, X. Castel, M. Himdi, G. Legeay, S. Vigneron, and E. Motta Cruz, "Ultrathin metal layer, ITO film and ITO/Cu/ITO multilayer towards transparent antenna," IET Science, Measurement and Technology, vol. 3, no. 3, pp. 229-234, 2009.

[6] C. C. Serra, C. R. Medeiros, J. R. Costa, and C. A. Fernandes, "Mirror-integrated transparent antenna for RFID application," IEEE Antennas and Wireless Propagation Letters, vol. 10, pp. 776-779, 2011.

[7] A. L. Popov, O. G. Vendik, and N. A. Zubova, "Magnetic field intensity in near field zone of loop antenna for RFID systems," Technical Physics Letters, vol. 36, no. 10, pp. 882-884, 2010.

[8] X. Qing, C. K. Goh, and Z. N. Chen, "Segmented loop antenna for UHF near-field RFID applications," Electronics Letters, vol. 45, no. 17, pp. 872-873, 2009.

[9] X. Li and Z. Yang, "Dual-printed-dipoles reader antenna for UHF near-field RFID applications," IEEE Antennas and Wireless Propagation Letters, vol. 10, pp. 239-242, 2011. 

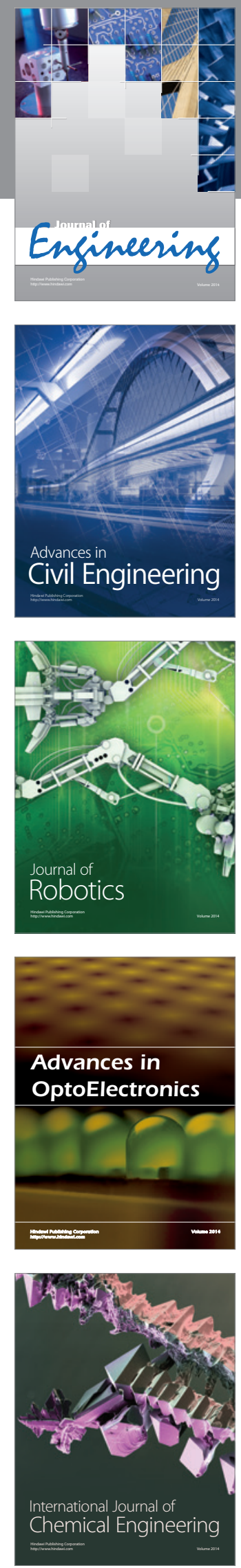

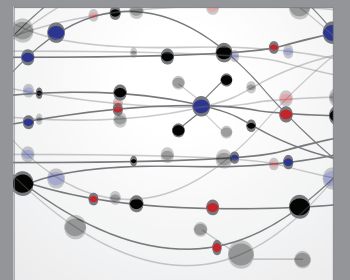

The Scientific World Journal
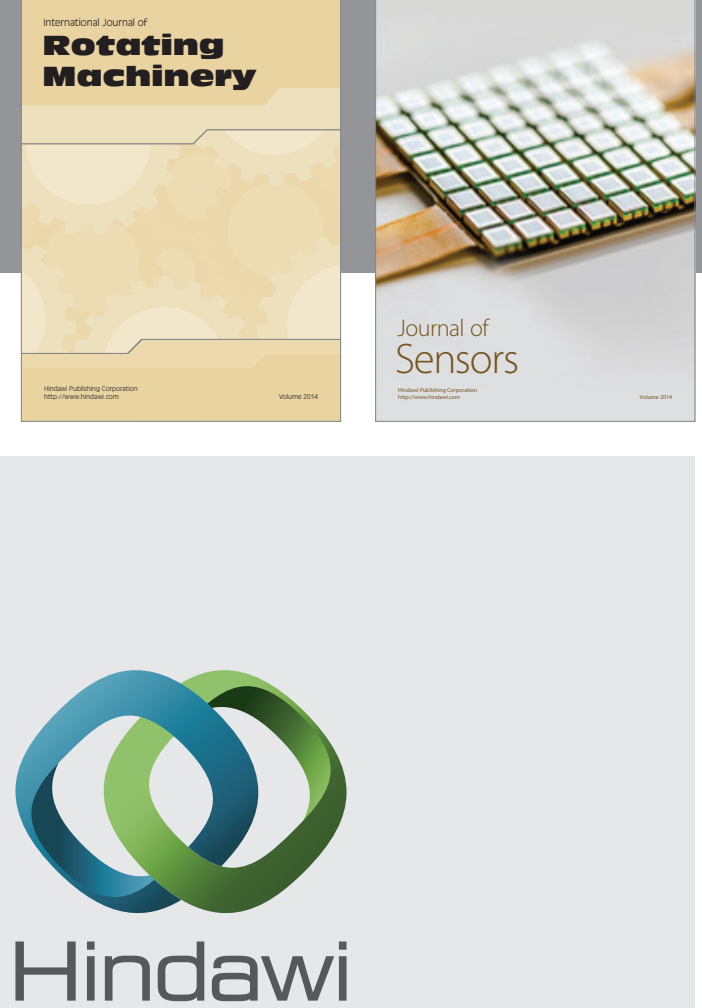

Submit your manuscripts at http://www.hindawi.com
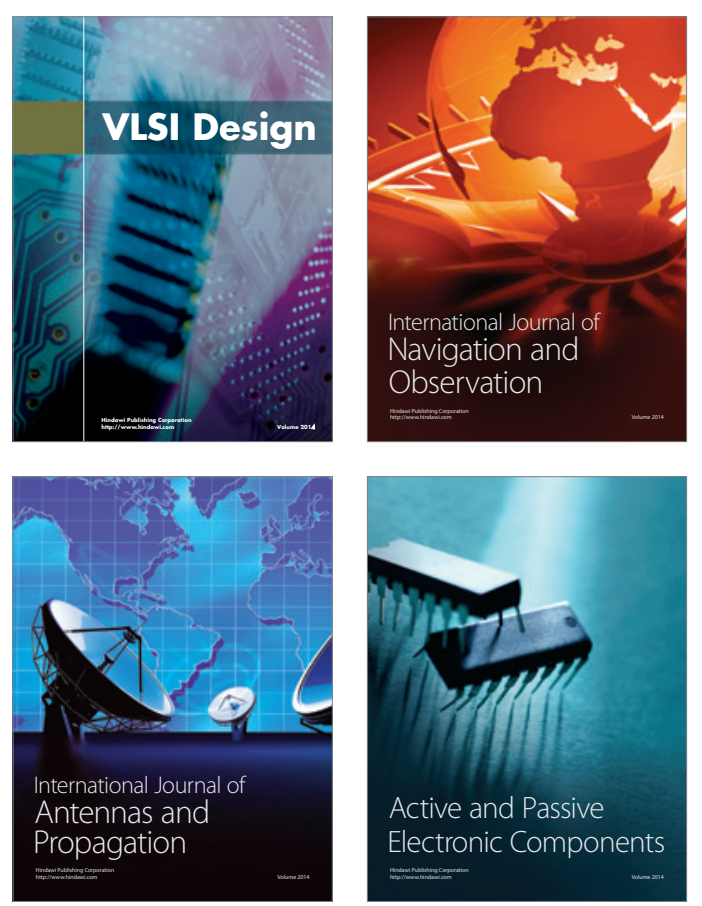
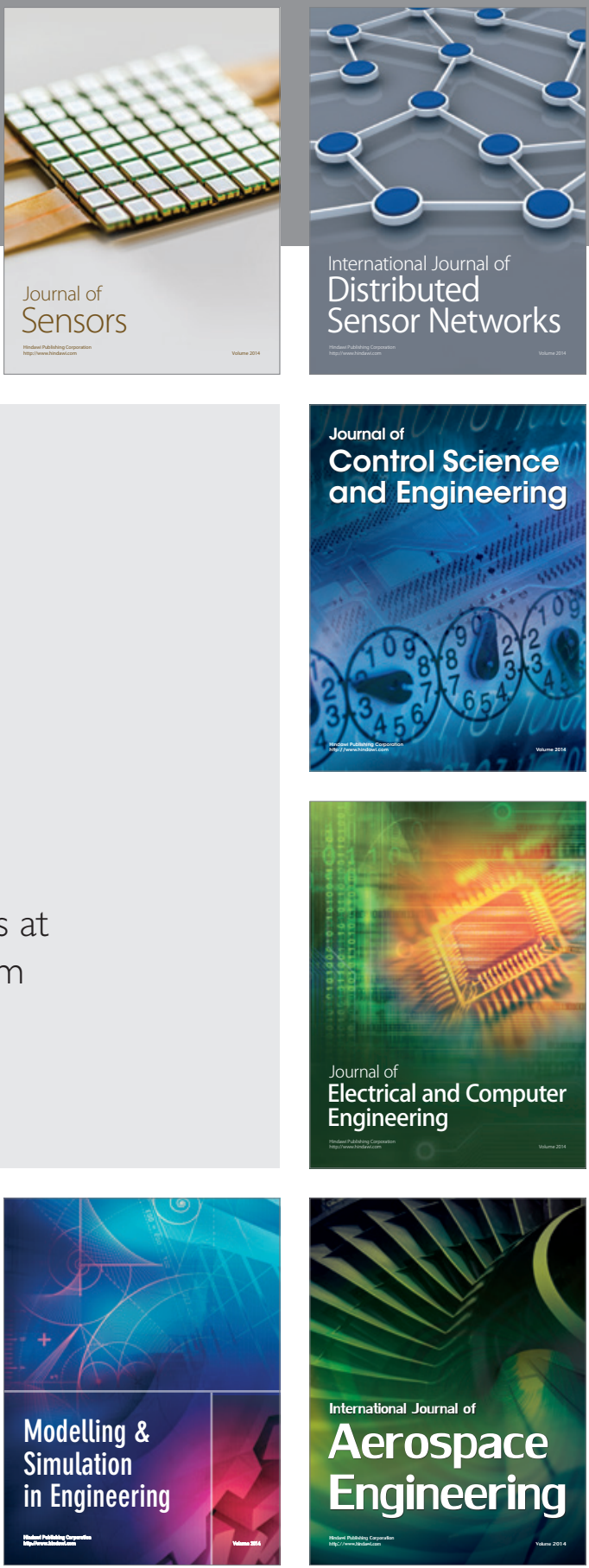

Journal of

Control Science

and Engineering
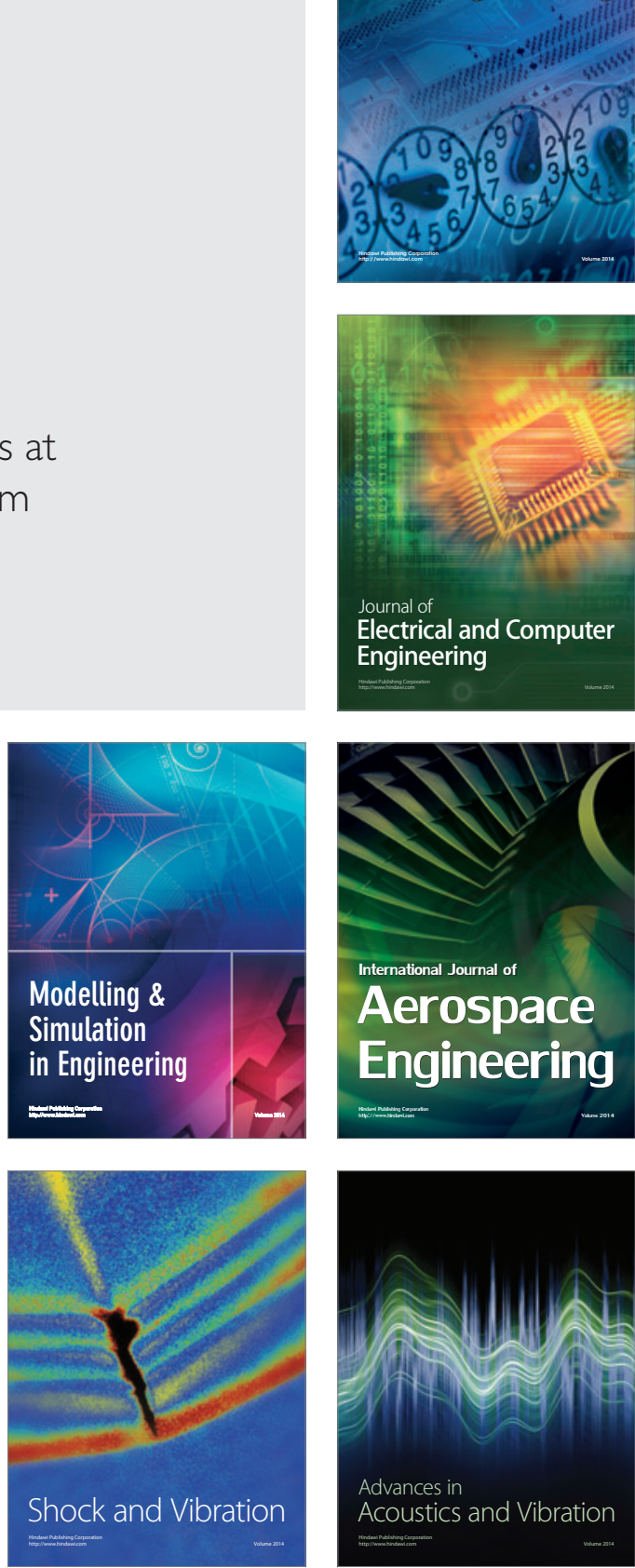